\title{
Justification of a Multidisciplinary Approach to Teaching Language in Botswana Junior Secondary Schools
}

\section{Deborah Adeninhun Adeyemi}

\begin{abstract}
It is often the case that teachers grapple with approaches to classroom instruction at all levels of education. Generally, educators and students are used to the delivery of instruction through the subject or the disciplinary approach. Teachers and researchers are today arguing for the use of more than one discipline to teach or clarify a concept or an issue by bringing forth the relationship and the contribution of various disciplines for a better understanding of the topic, theme or the content under study. This paper attempts to clarify the concepts of the disciplinary, interdisciplinary and the multidisciplinary/integrated approaches to instructional delivery. It also builds a rationale for the use of the interdisciplinary and the multidisciplinary approaches to instruction in Botswana schools. Finally, the paper provides a brief illustration of the teaching of a concept with the use of the multidisciplinary approaches with the attendant implications for pedagogy.
\end{abstract}

Key Words: Rationale, Subject, Interdisciplinary, Multidisciplinary, Integration, Curriculum, Language.

\section{Introduction}

One of the burning issues in the field of education today is an effective pedagogic practice enhance learning. Seminars and workshops have been conducted by educational scholars at the local and national levels in Botswana to find appropriate approaches of delivering content to students in order to bring about the desired changes. Also, educators all over the world continuously search for quality methods and approaches to teaching, Botswana as a country is not left out in the quest for quality education in terms of the approaches to teaching and learning in schools.

Botswana is situated in Southern Africa. The Southern African region consists of ten countries namely: Angola, Botswana, Lesotho, Malawi, Mozambique, Namibia, South Africa, Swaziland, Zambia and Zimbabwe. Botswana, formerly known as the 
Bechuanaland Protectorate, became independent in 1966. The country was ruled by the British between 1885 and 1965. As a result of her past colonial contact, English is very important in Botswana. It is an official language in the country and a medium of instruction in schools and institutions of higher learning. It is a major language of communication within the country, the Southern African region of which Botswana is a member, the continent of Africa and globally (Mooko, 1996).

After independence, efforts were made through various education policies to enhance teaching and learning in educational institutions and particularly in the area of language instruction. This is with reference to the teaching of the English (the official language and medium of instruction) and Setswana (the national language) (Republic of Botswana, 1977, Republic of Botswana, 1994). These documents have envisioned the effective preparation of students for life, citizenship and world of work. In addition, modern trends dictate the necessity for highly proficient skills in English and other foreign languages in a global environment.

It then follows that every citizen of Botswana is expected to demonstrate a high degree of proficiency in the languages. The English language and Setswana are taught at all the junior secondary schools in Botswana. Lately, the teaching of French has started in some selected junior secondary schools. The recommended approach to teaching language at all levels of the basic education programme in Botswana is the communicative approach where students are expected to learn the functions and use of language in meaningful interactions, communicative activities and problem solving tasks, reflecting the integration of the four language skills of reading, writing, listening and speaking (Republic of Botswana, 1996). This paper intends to argue for the extension of the teaching of language across the curriculum because there is an evident gap that needs to be addressed in this area. It is the view of this writer that the teaching of the English language should reflect its utility not only in the language, but in all disciplines across the curriculum; that the knowledge acquired in learning the languages can equally be applied to the acquisition of knowledge in other content areas across the disciplines. 


\section{Objectives of this Paper}

The objectives of this paper are:

1. To explain the concepts of the subject (disciplinary), interdisciplinary, and multidisciplinary or integrated approaches to teaching;

2. To justify or develop a rationale for the use of the interdisciplinary /multidisciplinary instruction to the teaching of language at the junior secondary classroom in Botswana; and

3. To give a brief illustration of the teaching of a concept with the use of the multidisciplinary instruction using Setswana, English language and other disciplines.

\section{Explanation of Concepts}

For the purpose of this paper, three concepts are very important. They are the subject, the interdisciplinary, and the multidisciplinary or the integrated approaches to teaching and learning. The simple descriptions of the terms are given below:

The Subject Approach: This approach is also known as the traditional disciplinary approach as each subject is separately taught by the teacher in the area of the particular subject in question. For instance, language was traditionally taught as a subject with different compartments of reading, grammar, writing, and literature as separate components of the language skills. The use of a single academic discipline to teach is what is referred to as subject approach. For example, language was taught as a separate subject from other subjects. English was taught as being different from Setswana, Environmental Science, Mathematics, History and so on. In this way, each subject has a well defined boundary from which there is no connection to the other. 
The single subject approach is still reflected in the senior secondary and post secondary curriculums in Botswana and the onus is on the teacher to initiate the connections. The assumption for this situation is generally based on the premise that, the subject is a store house of facts, methods, theories, concepts and generalizations. Disciplines here then, focus more on the content rather than the process.

The Interdisciplinary Approach: As the name suggests, it is an approach of using two subjects in teaching a topic, concept or theme. In this case, the English language teacher may explore similar concepts in both Setswana and English to teach a topic, theme or concept to bring out the interrelationships between the two languages. Examples of other subjects in this category are Biology and Zoology taught in combination as Biology, and Biology and Chemistry taught as Biochemistry to illustrate the relationship between the two disciplines.

The multidisciplinary approach denotes the teaching of concepts across more than two subjects or disciplines. The instruction may be organized on fundamental issues common to the three academic disciplines instead of teaching the students in a disjointed and unconnected manner. Examples of the multidisciplinary approach can be illustrated by Integrated Social Studies (Geography, Political Science, Sociology, Psychology), and Integrated Science (Biology, Chemistry, and Physics) as reflected in the junior secondary curriculum in Botswana. The use of the multidisciplinary approach in instruction can equally be referred to as the integrated approach. Integration, in this sense means using relevant ideas from many other disciplines to, 'do justice' to the topic or problem at hand. Aina (1979) says of integration:

Integration can be used within and across disciplines. Language, for instance, can be taught in itself (within) to integrate the four skills of listening, reading, writing, and speaking, as well as across to integrate concepts, themes and ideas from the different subject spectrums. This is an approach favoured by several authors based on the premise that practical experiences of life suggest that solutions to problems of living are not found in the study of separate school subjects (Aina, 1979). 


\section{Justification for Multidisciplinary Instruction in Botswana Schools}

Multidisciplinary instruction is an approach that thoughtfully incorporates and connects key concepts and skills from many disciplines into the presentation of a single unit. Langa and Yost (2007:65) add that it is a methodology to help students make connections. Mathison and Maston (1989) observe that multidisciplinary instruction helps students connect and use information that they have learned from one discipline to address the problem at hand. Also, Lucan (1981:59) argues that:

A child sees the world as one unit and naturally asks questions which cut across artificial subject divisions. An integrated approach to learning attempts to follow the child's natural ways of learning, viewing the world as a whole, the teacher's role being to provide experiences and to assist the process by suggesting further lines that may be followed.

It can be deduced therefore that the approach is learner-centred as it empowers students to see the connections, generalize and transfer knowledge to a variety of problem solving situations in the real world. In addition, it enables students gain and apply knowledge, skills and strategies in multiple subject areas that allow them to construct a more integrated web of knowledge and information.

Furthermore, multidisciplinary instruction provides learners with a more comprehensive learning that is rich and interesting. The fact that the different disciplines borrow knowledge from each other potentially makes the classroom amusing and thought provoking. This is supported by Bansford, Brown and Cockin (2002) when they state that integrating learning through multiple disciplines provides students with a more comprehensive learning experience that unifies, and a greater understanding than that which could be obtained by examining the parts separately.

More importantly, multidisciplinary instruction allows for the use of literacy activities. This is especially beneficial in language teaching and learning. Through the implementation of read-aloud, guided reading and independent reading, students are 
provided with multiple opportunities to develop content knowledge. In English, story telling can be an important avenue for constructing knowledge in Science, Art and Social Studies and so on. Again, commenting on this idea, Tomasino (1993) says that a good cultural literature and relevant social studies activities reveal peoples' similarities and differences and develop cultural literacy. Furthermore, Knowles and Smith, (2001:77) see the value of integration in the teaching of literature in language as below:

More and more emphasis has been placed on the power of literature to integrate curriculum, linking disciplines through literature provides a richer, more meaningful understanding of subject matter ... Linking disciplines with literature can facilitate collaborative learning as well as help students become independent problem solvers.

Moreover, the use of the multidisciplinary approach permits the teacher to combine a variety of methods, techniques and technological devices. In fact, it is believed that multidisciplinary teaching gets the whole school, teachers, parents and community involved. This is because it facilitates team and collaborative activities. Teachers share classroom activities, worksheets and resources with each other to facilitate their students' learning. The parents also get involved as they work collaboratively with teachers to address students' learning needs and issues. Students also learn collaboratively as they do group or pair projects and presentations. In fact, everyone benefits as the students see their curriculum come alive to address issues in the classrooms, across subject areas, in the school as a whole, as well as in the community. It is assumed that the greater the level of integration desired, the higher the level of collaboration required in multidisciplinary instruction.

Adeyemi (1979) in his investigation of the teaching of Social Studies observed that the Social Studies teachers who used the integrated approach to teaching performed better than other teachers who used the subject approach. Also, various authors as illustrated earlier have supported the use of integrated instruction. 
Furthermore, integrated approach to the teaching and learning of English language and Setswana at the junior secondary school level in Botswana is justified by the National Commission on Education (NCE) (Republic of Botswana, 1993: 153) which states that the compartmentalization of subjects should be avoided and every effort should be made to establish linkages between the subjects in a holistic way.

All the above justifications and benefits of multidisciplinary instruction probably informs the Revised National Policy on Education (RNPE) (Republic of Botswana, 1994) which recognizes the role of English as a service subject that helps to bring different insights into content materials across the curriculum. Also, a section of the junior secondary syllabus (Republic of Botswana, 1996) with regard to the teaching of grammar in language, stresses that it is preferable that grammar be taught as an integrated component of all language skills rather than in isolation. To this end, grammar is infused into instructional objectives, and not itemized to be taught separately (Republic of Botswana, 1996: ii) in recognition of the benefits of integrated teaching. Finally, The Revised National Policy on Education recommendation 17 (Republic of Botswana, 1994) in relation to integration in instruction calls for the formulation of a policy on curriculum development which should include a framework for integrating new subjects, themes, issues into the existing curriculum. In an attempt to implement this, the junior secondary school curriculum (Republic of Botswana, 1996) is designed to include the teaching and learning of integrated disciplines as illustrated in the subsequent discussions.

\section{Some Integrated School Subjects in Botswana}

The highlighted junior secondary school subjects are recommended to be taught in consideration of the multidisciplinary or integrated approach. Language Teaching (Setswana and English): The teaching of the languages embrace two integrated components of language and literature and the teaching of the four language skills within the language components. Literature is also taught as a component of the English language and not apart from it. Social Studies is also taught, fully integrated. It 
comprises of three components: History, Geography and Development Studies within the single Social Studies discipline. Integrated Science comprises of the three sciences of Biology, Chemistry and Physics which is taught collectively as one subject at this level. Finally, Home Economics is also taught at this level to integrate fashion and fabrics, home management and food and nutrition. These are just a few of the junior secondary school subjects that are visualized to be taught in the multidisciplinary/integrated approach.

It can be concluded that the Botswana junior secondary education system favours integrated instruction. However, the general observation is that even though the curriculum favours the multidisciplinary approach, the actual teaching of the subjects most often does not connect them from observed teacher practices. Teachers still prefer to limit themselves to their traditional subject compartments. Thus a teacher with a history background would emphasize that aspect in teaching Social Studies or emphasize geography more than other aspects of Social Studies if they had a Geography background. Same principles apply to the teaching of the Sciences in other cases. The question of the practical demonstration of the ideals of integrated instruction and how it can be effectively implemented will be outlined in this discussion.

\section{Collaboration in Integrated Instruction}

The notion of multidisciplinary instruction assumes that a topic, concept or theme is better taught and understood when more than one subject is involved in the teaching and learning of the subject matter. The approach also recognizes and values the role of other stakeholders in the educational process such as, collaborative teaching teams, subject clusters, parental and community involvement in teaching, and other collaborative school activities. To heighten the sense of collaboration needed in integrated instruction, Hennings (2000) says that teachers today are unleashing the power of communication by introducing learning strategies that rely on social interaction, dialogue and collaboration. She states further: 
In teaching language for instance, one needs to look at aspects of language such as speaking, reading, writing and listening. Again in teaching a composition topic such as, 'Advertising' will use music, art, technology, psychology etc. to teach effectively (Hennings, 2000:8).

From all of these, it can be argued that, the teaching of the languages - English and Setswana and literature in Botswana junior secondary schools may encourage critical awareness of related concepts across the curriculum such as justice, the environment, citizenship, human rights, moral and emotional development, family, and community life in ways that touch on personal and social experiences. It also makes sense to assume that such integration of disciplines to the teaching of language can help to develop morals and value judgments. Students can, at the same time have the added advantage of increasing their knowledge of vocabulary of the disciplines while working on related topics in the different subject areas.

The teaching of the concepts related to language should employ practical and reflective strategies in the teaching of topics associated with other subjects in the school curriculum. This can be done by teaching across the subject boundaries (Jweid and Rizzo, 2004). The teaching of a concept using the multidisciplinary approach is in line with the philosophy of Gestalt' theory that, 'the whole is greater than the sum of its parts'. This implies that the teaching of a concept, not with the use of only one discipline, but with the use of three or more disciplines or subjects will aid better understand of the phenomenon under study. This approach will enable learners to ask questions which cut across artificial subject divisions and see the whole exercise from a 'holistic' angle. In this way, related subjects are utilized in teaching and ultimately make connections between and among disciplines toward a better understanding of humans and their interaction with their total environment. After all, this is a principal aim of education irrespective of people or boundaries.

\section{An Illustration of Teaching the Concept of Family with the Use of Multidisciplinary Instruction}


As indicated earlier in this paper, multidisciplinary instruction allows learners to become involved in comprehensive instruction. Consequently, an attempt will be made to briefly illustrate the teaching of the concept of 'Family' through the multidisciplinary approach with the use of Moral Education, Social Studies, English and Setswana which are core subjects at the junior secondary level in Botswana. The teachers of these subjects can come together to plan instructional units on identified themes, concepts or topics. Students would then be expected to borrow from these disciplines to tackle issues and skills in language learning.

For example, the theme of 'Family' is covered in English language teaching, 'Lelwapa' in Setswana, meaning family institution. In Social Studies, it is discussed as, 'family institution'. Students can also explore the same theme in Moral Education, discussed as, 'cultural values related to family life in Botswana' to mention just a few of the disciplines that incorporate the theme.

In the English outline scheme of work, students may cover the following skills in connection with the theme:

Reading: A passage about 'My family'.

Listening: How family members help at home.

Speaking: A brief talk on, 'My family tree'.

Writing: What family members do at home.

In Setswana, students may do the following:

Reading: The Traditional Family

Listening: The modern nuclear family

Speaking: Debate: The Modern versus Traditional Family (Which is better?)

Writing: A letter to a friend about my family.

In Moral Education students may: 
- $\quad$ Describe different types of family;

- Describe the role of family in the moral development of a child;

- $\quad$ Identify ways in which people are socialized; and

- $\quad$ Explain the cultural norms and values of family life in Botswana.

In Social Studies, students may:

- $\quad$ Explain and define the concept of family;

- $\quad$ Give types of family;

- $\quad$ Explain the responsibilities of men and women in the family and society; and

- $\quad$ Describe ways in which the family as an institution is part of the culture.

The suggested examples outlined are not rigid prescriptions. They can be modified to include parents to resource students on the theme about past and present family practices and norms to make it real to life for the students. Also, a lot more creative activities such as drawings, cartoons, poems and stories can be woven around the theme.

All the above activities indicate that the theme or concept of family cuts across many school disciplines, showing the interrelationship within syllabus which consequently, makes the mapping of themes easier for the willing teachers. Most importantly, it is evident that the junior secondary curriculum caters for integration. The curriculum is further made relevant by presenting information to students in a thematic holistic manner. This type of integrated learning empowers students to see connections, generalize and transfer knowledge to a variety of problem solving situations in real life.

\section{Pedagogical Implications of Integrated Instruction}

Appropriate teaching methods that address the individual and collective needs of students are required in the teaching and learning continuum. The use of different approaches to improve learning should always be explored by teachers who are intent 
on making a difference. Integrated instruction is one of the options available for effective instruction at the junior secondary level in Botswana for laying the foundation upon which academic habits can be inculcated in students.

For teachers of language, it is important that their methods and approaches aim towards the all round development and welfare of the taught taking into consideration their needs, problems, abilities and limitations. Integrated instruction provides the scope for this. Towards this realization, teacher education should provide exposure to integrated instruction to students as teacher training institutions seem to lack in this area or fail to provide adequate orientation to integrated teaching.

Professional training of teachers should also incorporate multidisciplinary methods for both pre and in service teachers. In order to enjoy the credit of professional efficiency, in-service teachers must encourage collaborative activities within and outside the school setting. Collaboration between the schools and academia should be strengthened to provide extension lectures, seminars on research, refresher courses, exhibitions, and current trends/innovations in instructional approaches that should not be confined to the ivory towers of higher institutions, but made available to the stake holders.

\section{Conclusion}

Multidisciplinary/integrated instruction is very vital in the present global era because of the belief that the global world is a culturally and linguistically diverse entity that can best be understood in an integrated way. As an innovation, it tries to rectify the divisive effects that the old traditional concept of learning as a discipline, pursued in the study of subjects, has upon the child's concept of knowledge. Multidisciplinary instruction enables learners to recognize contrasting perspectives, synthesize, think critically, and re-examine the world we take for granted (Davis, 1997). It makes students tackle meaningful but complex issues in a meaningful way as illustrated in this paper. Therefore, it is a learning approach that should be explored, encouraged and made easy for teachers to utilize in instruction. Finally, it is an area of knowledge that is open to more research to determine the extent of its use in actual instruction practices. 


\section{References}

Aina, N. F. (1979). Social Studies for Primary School Teachers. Ibadan, Nigeria: Oxford University Press.

Adeyemi M. B. (1979). A Study of Secondary School Teachers' Views on the Teaching of Integrated Social Studies in Oyo State of Nigeria. An unpublished Masters Dissertation of the Obafemi Awolowo University. Ile-Ife, Nigeria.

Bransford, J. D., Brown, A. L. and Cockin, R. R. (2002. How People Learn: Brain, Mind, Experience and School. Washington, D. C.: National Academy Press.

Davis, J. R. (1997). Interdisciplinary Courses and Team Teaching. Phoenix: American Council on Education/Oryx Press Series on Higher Education.

Hennings, D. G. (2000). Communication, Language and Literacy Learning. Boston: Houghton Mifflin.

Jweid R, Rizzo M 2004. Building Character through Multicultural Literature, Linham, MA: Scarecrow Press

Knowles E, Smith M 2001. Reading rules! Motivating Teens to Read. Englewood Cliffs, New Jersey: Libraries Unlimited, Inc.

Mathison, C. and Maston, C. (1989). Planning interdisciplinary curriculum: a systematic and cooperative approach. ASCD Annual Conference, Orlando, Florida.

Mooko, T. (1996). An investigation into the impact of guided peer feedback and guided self-assessment on the quality of compositions written by secondary school students in Botswana. Unpublished Doctoral Dissertation, University of Essex.

Lucan T A 1981. Social Studies as an integrated subject. In: Mehlinger, H. D. (Ed.): UNESCO Handbook for the Teaching of Social Studies, Paris: UNESCO.

Langa, M. A. and Yost, J. L. (2007). Curriculum Mapping for Differentiated Instruction. New York: The Dryden Press.

Republic of Botswana (1996). Three-Year Junior Secondary English Syllabus, Gaborone: Department of Curriculum and Evaluation.

Republic of Botswana (1994). Revised National Policy on Education (RNPE). Gaborone: Government Printers.

Republic of Botswana (1993). Report of the National Commission on Education. Gaborone, Botswana: Government Printer.

Republic of Botswana (1977). National Policy on Education, Gaborone: Government Printer. 